\title{
Educação musical interativa: propostas interdisciplinares para as tecnologias educacionais
}

Interactive Music Education: interdisciplinary proposals to educational technologies

\author{
Jair dos Santos Gonçalves ${ }^{1}$ \\ Universidade Federal de Santa Maria \\ Andréia Machado de Oliveira² \\ Universidade Federal de Santa Maria
}

\section{Resumo}

Este artigo visa refletir sobre objetos técnicos, estéticos e interativos e suas possibilidades de interdisciplinaridade para a área de Educação Musical e Artes Visuais, dentro de perspectivas da arte contemporânea e das Tecnologias Educacionais em Rede. Com caráter empírico/qualitativo, almeja pensar na formação educativo-visual-musical através da utilização de Tecnologias da Informação e Comunicação (TIC), da Performance Musical, da Composição e da Música Visual. Como prática, a pesquisa buscou compreender as poéticas e narrativas sonoras por meio de atividades de interpretação sonoro-musical de performances visuais e corporais, utilizando-se do recurso da Música Visual de modo interativo. Os trabalhos resultaram na produção de uma composição, de estilo improvisatório livre, por uma orquestra estudantil, de uma escola de uma cidade do estado do Rio Grande do Sul.

Palavras chave: Música Visual; Educação Musical Interativa; Tecnologias Educacionais, Artes Visuais.

\section{Abstract}

This article aims to reflect on interactive, aesthetic, and technical objects and their interdisciplinary possibilities for the field of Music Education and Visual Arts within the perspectives of contemporary art and Networked Educational Technologies. With an empirical / qualitative character, it aims to think about the visual-music-educational

\footnotetext{
1 Autor da pesquisa. Mestrado em Tecnologias Educacionais em Rede/PPGTER/UFSM, 2014. Especialista em TIC aplicadas à Educação/CAL/UFSM, 2014, Graduado em Música/UFSM, 2012. E-mail: audio1produtora@yahoo.com.br 2 Orientadora da pesquisa. Doutora em Informática na Educação pela Universidade Federal do Rio Grande do Sul/UFRGS Brasil e pela Université de Montreal/UdM - Canadá, Mestre em Psicologia Social e Institucional pela UFRGS e Graduada em Bacharelado e Licenciatura em Artes Visuais pela UFRGS. Professora do PPGART e PPGTER da UFSM.
}

Revista Digital do LAV - Santa Maria - vol. 9, n. 1, p. 103 - 127. - jan./abr. 2016 ISSN 1983 - 7348 http://dx.doi.org/10.5902/1983734819521 
training through the use of Information and Communication Technologies (ICT), Musical Performance, Composition and Visual Music. As practice, the research sought to understand the poetics and sound narratives by means of sound-musical interpretation of visual and physical performances, making use of Visual Music resources interactively. The work resulted in the production of a free, improvisatory style composition, by a student orchestra, from a school in a city in the state of Rio Grande do Sul.

Keywords: Visual Music; Interactive Music Education; Networked Educational Technology.

\section{Introdução}

A presente pesquisa ${ }^{3}$ busca contribuir com uma reflexão sobre objetos tecnoestéticos interativos voltados para a Educação e suas possibilidades de interdisciplinaridade para a área de Educação Musical e Artes Visuais, dentro de perspectivas da arte contemporânea. A principal questão investigada consiste em como a mediação das Tecnologias de Informação e Comunicação (TIC), como recurso que possibilite interdisciplinaridade entre os diversos campos da Arte, em especial as Artes Visuais e a Música, pode promover um Ensino Musical Interativo a partir de propostas pedagógicas em Musica Visual.

A pesquisa tem como objetivo geral, buscar desenvolver propostas pedagógicas utilizando recursos tecno-estéticos com um grupo de Orquestra Estudantil. Neste sentido, necessita-se de estudos metodológicos no tocante a uma Educação Musical Interativa4. Sob tal perspectiva, são elencados objetivos específicos através dos quais investigam-se objetos tecno-estéticos interativos e suas possibilidades de interdisciplinaridade com a área de Educação Musical, tendo o escopo de criar propostas pedagógicas e metodologias interdisciplinares dentro do campo da Música Visual. Além disto, busca-se compreender como a utilização de tecnologias digitais pode auxiliar nos processos de ensino e aprendizagem de música em espaços escolares; pensar propostas interdisciplinares onde se possa produzir música visual utilizando dispositivos móveis; compreender as relações entre apreciação musical favorecida por TIC e as implicações para aprendizados musicais

\footnotetext{
${ }^{3}$ Este artigo tem como referência a pesquisa de mestrado "EDUCAÇÃO MUSICAL INTERATIVA: RECURSOS DA MUSICA VISUAL PARA AS TECNOLOGIAS EDUCACIONAIS EM REDE" de Jair dos Santos Gonçalves. 4 Educação Musical Interativa: conceito defendido pelo autor que expressa a ideia de um processo de Educação Musical significativo, baseado na utilização de recursos das TIC, e que proporciona a interdisciplinaridade e interatividade através dessa utilização.
} 
interativos, sendo que isto torna possível a compreensão das motivações dos estudantes quando se dá a utilização de recursos como computadores, mídias locativas e vídeos, em sala de aula.

O campo empírico dessa pesquisa é a Orquestra Estudantil, que conta com o apoio de gestores educacionais, desde 2011. O projeto da Orquestra Estudantil prevê atividades musicais, que envolvem estudantes de escolas de Ijuí/RS. É focado o ensino de instrumentos de orquestra, educação musical, prática em grupo e individual, performances, apreciação, composição e teoria musical.

O campo epistemológico das Artes em que se insere a Educação Musical necessita de estudos no tocante a uma Educação Musical Interativa. É necessário pensar como a Música pode se tornar Música Interativa e que, com esta característica, comece a fazer parte de práticas pedagógicas inovadoras, bem como sejam pesquisados objetos de ensino e aprendizagem de música, através destes meios.

Neste sentido, faz-se um estudo sobre o estado da arte da Música Visual. São destacados os principais conceitos, pesquisadores e obras importantes em discussão até o presente momento. São descritas diversas experiências práticas realizadas, as quais visaram aplicação da metodologia adotada neste estudo. Ainda, é abordado o conceito de Educação Musical Interativa (EMI), sendo a união de conceitos, metodologias e pedagogias referentes à área da Educação Musical e Artes Visuais com a das TIC, considerando ainda o aspecto da interdisciplinaridade em relação à Musica Visual. Através deste diálogo entre as áreas, analisar-se-á a construção de propostas pedagógicas em Educação Musical Interativa, visto a grande dificuldade de encontrar objetos educacionais e aplicativos que visem o aprendizado visual musical. A exploração e estudo de softwares que transformem o som em imagem e a construção de "scripts"5, para serem usados no programa Processing 2.0, bem como sua disponibilização em rede.

A metodologia adotada é relacionada com o campo empírico qualitativo, tendo como teorias de base, autores como Sullivan (2009), proponente da Metodologia da Pesquisa Conduzida pela Prática e Prática Conduzida pela Pesquisa, e ainda, os de John Dewey, que refletem a importância da experiência empírica do sujeito, destacando assim a importância do aprender fazendo. Tem-se como referência a teoria de base acerca da

\footnotetext{
5 Nota: Script é um texto com uma série de instruções escritas para serem seguidas, ou por pessoas em peças teatrais ou programas televisivos, ou executadas por um programa de computador. O termo é uma redução da palavra inglesa manuscript, que significa "manuscrito", "escrito à mão". O script é o roteiro onde estão escritas todas as informações sobre os espetáculos audiovisuais (teatro, novelas, filmes e outros programas de rádio ou televisão). É um texto narrativo que contém informações para os atores ou apresentadores. (Fonte: http://www.significados.com.br/script/).
} 
Metodologia de Pesquisa Baseada em Arte, de McNiff (1998), uma vez que permite que se entenda o sujeito como parte integrante da pesquisa.

Como resultado de aplicação do estudo, estimou-se a apropriação do conceito de Música Visual pelos estudantes através de aulas práticas, onde ocorreram apreciações de filmes, bem como a criação de composições de estilo livre improvisatório, produção audiovisual, feitas com o grupo da Orquestra Estudantil. As composições criadas são o registro sonoro das interpretações realizadas de modo colaborativo, com os estudantes da orquestra.

Finalizando, realizou-se trabalhos em Música Visual, visando uma metodologia em Educação Musical Interativa, com o desenvolvimento de Scripts no software Processing e de uma composição com Musica Visual Interativa, utilizando o estilo musical da Improvisação Livre.

\section{Musica Visual: Revisão de Literatura}

Para dar conta da fundamentação teórica, são elencados conceitos operacionais importantes da Música Visual. As experiências no campo da música visual e experimental, como a música de improvisação livre e música aleatória, que são capazes de estimular a criatividade momentâneas, são empregadas como objetos de estudo dentro desta pesquisa. Almeida Jr. (2009), reflete quanto a música improvisatória que

O momento atual, marcado pela multiplicidade de informações, permite a convivência de várias possibilidades estéticas. Neste contexto, a retomada do uso da indeterminação, e um aproveitamento consciente da improvisação, poderão servir como meio para a busca de resultados expressivos mais espontâneos, o que, ao lado, por exemplo, dos recursos eletrônicos, oferece imenso campo de possibilidades. (ALMEIDA Jr. 2009, p. 10-11).

Além destas premissas, busca-se compreender ainda, o tema da Música Visual, sendo que, denota um gênero de música que envolve articulação com imagens, quer seja no processo de criação ou de performances, caracterizando um formato interdisciplinar com artes visuais. O arcabouço teórico, que serve de referência para estudar a Música Visual, são os estudos de Edward Zajec, Cornelia e Holger Lund, John Whitney, Oskar Fischinger, Willian Moritz, Norman McLaren, e autores brasileiros como Luis E. Castelões, e Sérgio Basbaum, tendo também referências dos trabalhos de artistas como Marco 
Donnarumma, Daito Manabe, e trabalhos expostos no CVM - (Center for Visual Music Centro de Música Visual) ${ }^{6}$.

Para Holger Lund (2009), a Música Visual começou como uma espécie de cinema ao vivo em raves e clubes, sendo que atualmente, existem produções feitas em estúdios que proporcionaram grande prestígio social a artistas e músicos visuais. O autor acredita que isto aconteceu devido à inter-relação entre as áreas de Cinema e Música, fato que possibilitou novas concepções artísticas e estéticas.

A atual Música Visual, segundo o autor, combina os dois elementos de forma diferente dos seus antecessores. Comparado a Música de Cor, a sua abordagem é mais técnica e com conteúdo mais dirigido, não apenas traduzindo música em luzes e cores. Tecnicamente, se nota uma diferença do filme experimental sendo que este reside no foco dado à música e à edição dos elementos visuais, em tempo real.

Segundo Lund, os trabalhos da Visual Music se diferenciam dos videoclipes por serem sequenciados de forma cíclica ou associativa, sendo que, não tem intenção de formarem narrativas. Porém, as fronteiras dos videoclipes estão indefinidas, visto existir uma evolução recente onde se documentam produções ao vivo ou de estúdio de música visual, através das quais, se mostra o VJ (Vídeo Jockey ou Visual Jockey), atuando de modo parecido ao DJ (Disk Jockey), cujos métodos de trabalho têm uma série de semelhanças. O trabalho destes VJs reside da elaboração de concepção visual em eventos como os dos DJs. Seu trabalho consiste em selecionar um repertório de vídeos e sequências de animação, misturando-os, de modo que exista relação rítmica destes com a música. É um processo de combinação e de mistura de sons e imagens em tempo real. $\mathrm{O}$ autor pondera que os VJs costumam usar materiais próprios, tais como sequências pré-programadas ou gravações ao vivo de imagens.

Como se percebe, o tema da Música Visual é bastante profuso. Vem sendo amplamente investigado por artistas e pesquisadores de diversas áreas ligadas a arte, música e tecnologias. Salles (2002), faz um resgate da associação do som com a imagem afirmando que

os primeiros registros históricos que contém alguma referência à associação som/imagem são de origem religiosa, que tratavam de unir num mesmo acontecimento formas visuais (ritos, encenações) com música ou sons (mantras, textos sagrados). Apesar de não podermos reproduzir com precisão todos os detalhes destes rituais antigos, é certo que eles muito provavelmente foram os

6 - Site do CVM : http://www.centerforvisualmusic.org/

Revista Digital do LAV - Santa Maria - vol. 9, n. 1, p. 103 - 127. - jan./abr. 2016 http://dx.doi.org/10.5902/1983734819521 
precursores, num sentido prático, da formação do paradigma som/imagem7. (SALLES, 2002, s/p).

O autor traz em sua pesquisa, informações importantes sobre os primeiros registros associando som e imagem, citando como exemplo a tradição da cultura ocidental Judaico-Cristã, onde cita o livro de Gênesis e a narrativa da criação do mundo através da emissão da frase "faça-se luz", e a partir disto, as primeiras formas visuais passam a se revelar no universo, como conta o referido livro bíblico. O autor acredita que

[...] a cosmogonia bíblica indica claramente o caráter imemorial e indissolúvel da união do som e da imagem, narrando "No princípio, Deus criou os céus e a terra. A terra, porém, estava informe e vazia, as trevas cobriam o abismo, e o Espírito de Deus pairava sobre as águas. Deus disse: 'Faça-se a Luz! (Gênesis, I, 1-3)" A criação dos céus e da terra prescinde do som, da palavra; a criação da luz, porém, é concomitante ao verbo, que pressupõe o som proferido na ordem: "Faça-se a Luz! - e a luz se fez" (SALLES, $2002, \mathrm{~s} / \mathrm{p})$.

Outro resgate histórico, trazido pelo autor, busca também associação à ideia de "Música das Esferas", teorizado por Pitágoras (586 a.C), sendo que o sentido deste conceito é dado, de modo que, ao relacionarem-se elementos sonoros às vibrações e movimentos de astros do espaço sideral, obtém-se harmonia entre os sons e o universo. Para o autor, ainda na Grécia

[...] não podemos deixar de mencionar Pitágoras, cujo sistema filosófico girava em torno de um conceito bastante próximo de nossas investigações: a Música das Esferas era uma relação de harmonia entre os sons e o universo, em que cada planeta ou corpo celeste, ao vibrar, emitia um som, e o conjunto de sons de todos os corpos soava por todo o Universo. Este som era harmônico, e cada estrutura vibratória tinha um paralelo funcional. (SALLES, 2002, s/p) 8

Além disto, o autor pondera que existiram eventos profanos, destinados ao entretenimento como o teatro de sombras, através do qual fora possível que a música se unisse a diversos tipos de imagem. Isto traduz a diversidade do aspecto cultural e histórico da Música Visual. A associação direta da Cor com o Som, é descrita por Salles

7 - Fonte: Texto da tese digital no link http://www.mnemocine.com.br/filipe/tesemestrado/tesecap2.htm 8 - Fonte: http://www.mnemocine.com.br/filipe/tesemestrado/tesecap2.htm acessado em 24/08/2014 
(2002) ao ponderar que a relação "cores/tons" é percebida nas teorias de Newton sobre ótica. Estas ideias, conforme pondera o autor, também obtiveram importância histórica no estudo da Cor e Som. Segundo Salles (2002) "a primeira relação pesquisada cientificamente entre o som e a imagem foi a instância cromática $\mathbf{9}^{\prime \prime}$.

Ao afirmar isto, o autor aproxima esta premissa com as ideias de Newton, "uma vez que as cores são frequências do espectro eletromagnético e o som frequências mecânicas, mesmo sem que soubessem de suas distintas naturezas, a inter-relação entre ambos pela questão vibratória foi amplamente discutida", explica. Revela ainda, que é atribuído a Newton ter

[...] descoberto a composição da luz solar branca através de suas experiências com o prisma, imaginou que a luz era constituída por uma torrente de partículas e que sua transmissão se dava por ondas. Portanto, tais ondas deviam seguir a periodicidade de qualquer movimento vibratório, tendo freqüência e comprimento de onda. A similaridade com as ondas mecânicas do som neste aspecto é imediata, e Newton, tendo observado 7 cores na decomposição da luz (em referência direta com as 7 notas da escala diatônica), foi o primeiro a colocar comparativamente o som e a cor lado a lado, presumindo que cada cor corresponderia a uma nota. Desta maneira, produziu dois discos: um, famoso nas experiências escolares, contém as 7 cores do espectro visível, que, ao ser girado, tem como resultante o branco, e outro, em que as cores são associadas às notas, conforme a figura 1. (SALLES, 2002, p)

É interessante perceber a associação da cor com o som, através do prisma elaborado por Newton (Figura 1).

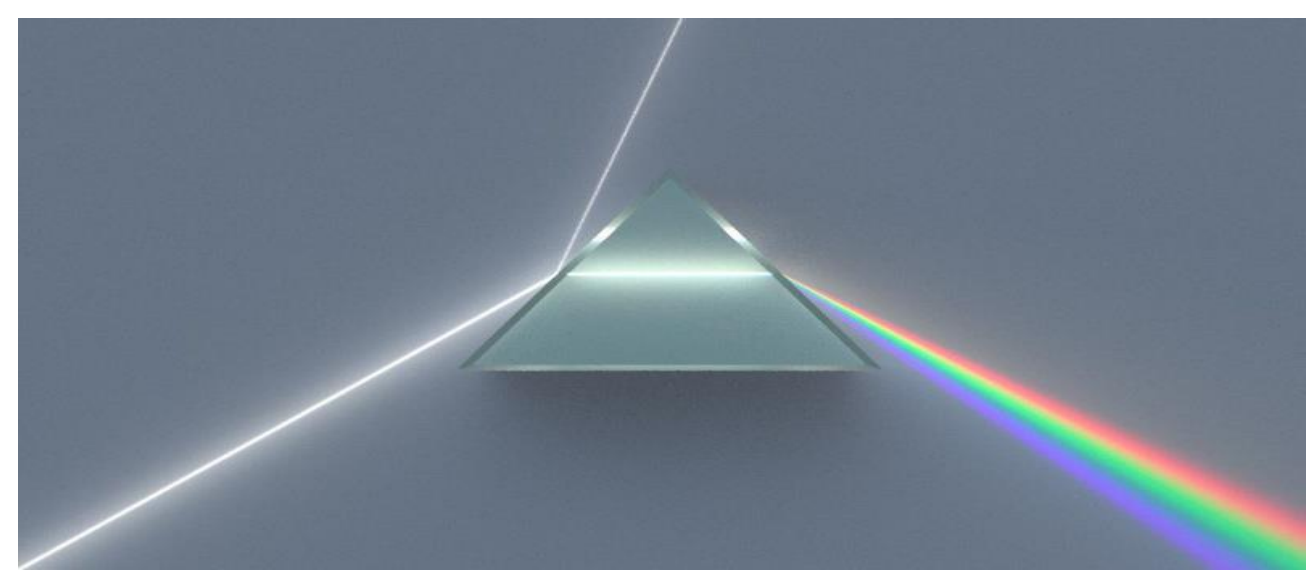

9 - Fonte: http://www.mnemocine.com.br/filipe/tesemestrado/tesecap4_3.htm acessado em 24/08/2014.

Revista Digital do LAV - Santa Maria - vol. 9, n. 1, p. 103 - 127. - jan./abr. 2016

ISSN $1983-7348$ http://dx.doi.org/10.5902/1983734819521 
Figura 1 - Prisma de Newton Fonte:

http://commons.wikimedia.org/wiki/File:Dispersive_Prism_Illustration_by_Spigget.jpg)

Pode-se ainda, através dos estudos de Salles (2002), fazer uma retrospectiva histórica, acerca da associação do som com a imagem. O que os estudiosos tinham em mente era organizar, as sete notas da música, em esquemas de cor. A nota Do, por exemplo podia ser representado por azul, o Ré, por vermelho e assim por diante.

São citados por exemplo, padre Kircher (1602-1680), padre Mersenne (15881648), e o padre Louis-Bertrand Castel (1688-1757), que em 1743, criou o famoso "Cravo Ocular", baseado na teoria de Newton, e, conforme o autor, "acrescenta o tratado de Harmonia de Rameau para criar um 'Órgão de Cores' (Cotte, 1995:29-30). Esta mesma descrição do Cravo Ocular é descrito por Moritz (1997) ao ponderar que

[...] o padre jesuíta Louis Bertrand Castel, construiu um "cravo ocular" por volta de 1730, que consistia em um quadro de 6 metros quadrados acima de um cravo normal; o quadro contém 60 pequenas janelas, cada um com um painel de vidro de cor diferente e uma pequena cortina ligada por polias de uma tecla específica, de modo que cada vez que a chave fosse atingida, a cortina levantava rapidamente para mostrar um brilho de cor correspondente...O compositor alemão Telemann viajou para a França para vê-lo, compôs algumas peças a serem tocadas no cravo Ocular, e escreveu um livro em alemão sobre o assunto10.(MORITZ, 1997,p.1)

Música Visual denota-se também como música que envolve articulação com imagens, quer seja no processo de criação ou de performance. As práticas relacionando Música e Imagem são bem mais antigas que o uso atual do termo "Música Visual", que, segundo as pesquisas, é recente. Tais estudos afirmam que

[...] a utilização sistemática nas artes, na comunicação e nos rituais da relação som imagem remonta há muito mais tempo do que podemos imaginar, sendo descritos exemplos desta simbiose em textos tão antigos como o Êxodo bíblico, a Teogonia de Hesíodo ou a Poética de Aristóteles. Todos relatam, de alguma forma, aspectos de criação oriundos de uma interação entre som e imagem. Para nosso universo ocidental, essa relação já era claramente utilizada no teatro grego, mas muito provavelmente tal prática de utilização de sons e música aliadas à ação dramática já

10 Nota: link indicado pela biblioteca digital do centro de música visual http://www.centerforvisualmusic.org/Library.htm|\#general. Link do texto do autor http://www.awn.com/mag/issue2.1/articles/moritz2.1.html. 
deveria ser de uso constante em civilizações muito mais antigas, como a hindu, a chinesa ou a egípcia. (SALLES, 2002, p. 2)

Além desta perspectiva histórica, é importante destacar que o desenvolvimento de estudos e teorias acerca de Música Visual são intensificados contemporaneamente, através dos avanços da tecnologia. Nessa perspectiva, pode-se afirmar que há a ligação entre as áreas de Arte, Tecnologia e Sinestesia, porquanto como afirma Basbaum (1999), a música visual unifica COR ou "cromo", e SOM "Sonia" e é amplificada por ter relevância artístico-cultural para estes campos. Sendo assim, pondera que

[...] a Cromossonia é uma hipótese artística. Em torno dela, porém, se agrupam diversas questões relevantes para o contexto artístico e cultural contemporâneo, e esta pesquisa faz uso desta proposta artística embrionária para perseguir estes temas de fundo, as relações entre a sinestesia, a arte e a tecnologia. São portanto fatos reais baseados numa ficção. (BASBAUM, 1999, p. 1)

Dois pesquisadores importantes no estudo do tema são Cornelia Lund e Holger Lund, os quais, publicaram recentemente o livro Audiovisual - On Visual Music and Related Media (2009). Este livro trata da discussão acadêmica sobre o tema da Música Visual, bem como apresenta paradigmas contemporâneos da práxis de criação audiovisual. Este livro é considerado pelos especialistas um guia histórico, uma vez que proporciona abordagens teóricas para se compreender e fazer música visual. Além disto, as pesquisas feitas por eles revelam perspectivas de músicos, artistas, curadores, diretores de festivais e desenvolvedores de software, visto que suas literaturas fornecem insights sobre o que está acontecendo na área experimental em questão.

Existem inúmeras propostas de Música Visual, que associam vídeo, dança, música, arquitetura e mídia locativa. Há relatos de grupos que desenvolvem performances, de tal modo que, seus integrantes (equipados com tablet, ou smartphone com conexão à internet) ao acessarem vídeo-danças, por exemplo, interagem da mesma forma ao se movimentarem em seus cotidianos. Existem pesquisas e performances que exploram morfologias espaciais, espaços ao ar livre, tais como lados e cantos de prédios, locais de arquitetura privilegiada aonde os atores interpretam (através da dança e movimentos corporais, por exemplo) e criam diversos modos de linguagem visual. Esses modos, por vezes, são produzidos por vídeos, softwares, sintetizadores, e outros recursos tecnológicos.

Esta perspectiva de compor narrativas, inspirando-se em cenários visuais reais, pode ser semelhante ao ato de criar uma composição musical baseada em Paisagem 
Sonora. O som (tal qual o movimento corporal oriundo da dança) pode revelar igualmente diferentes aspectos desta paisagem, ou seja, consegue trazer novos sentidos simbólicos (para a percepção humana) desta "arquitetura morfológica dos espaços" sendo ela, reinventada através da tecnologia, narrativas sonoras e visuais.

Como se pode averiguar, a prática musical pode ser pensada visualizando-se outras formas de aplicação, de modo que se consiga criar e recriar novas significações e narrativas artísticas, não só através de recursos tecno-estéticos interativos, mas também, por meio de procedimentos metodológicos, assistidas por aplicativos, dispositivos e softwares distintos. Essas tecnologias contribuem, portanto, para descrever e interpretar musicalmente a "topografia" dos diversos cenários urbanos e não urbanos encontrados. Intervenções e trabalhos que se utilizam da associação imagem-som propiciam a criação de composições musicais únicas, favorecendo experimentações artísticas mais significativas. Isto é facilitado, devido à soma de recursos do audiovisual tais como cortes, edições, looping, efeitos visuais, criação de espectros sonoros entre outras técnicas de produção neste campo.

Ainda, dentro da Musica Visual, um dos principais conceitos é o de Sinestesia, desenvolvido nas propostas pedagógicas dessa pesquisa. Este sugere duplo ou triplo despertar de sentidos (audição, visão, por exemplo) por uma única fonte propulsora de estímulo. Nesta pesquisa, se estuda o som e a imagem como principais fontes para o estímulo sinestésico, dado que tanto som como imagem, podem criar diferentes percepções desse som ou dessa imagem. Neste sentido pode-se afirmar que Sinestesia pode ser considerada um fenômeno neurológico que consiste na produção de duas sensações de natureza diferente por um único estímulo.

Esta Sinestesia se faz presente quando uma cor é ligada a uma impressão auditiva (audição colorida, fotismos) ou sons são ligados a uma impressão visual (fonismos), que remete ao conceito de Cromossonia. Esta explicação é encontrada na pesquisa de Basbaum (1999), autor dedicado ao campo da Música Visual, e que desenvolveu o conceito de Cromossonia ou Cromo Som, onde há a mistura dos conceitos de COR e SOM. Segundo o autor, a Cromossonia é um "processo de criação original, uma linguagem possível para trabalhar no universo da Sinestesia Som-Cor, e, dentre os elementos que integram o conjunto da proposta cromossômica, estão a definição de uma partícula mínima, o que chama de cromo-som" (p.97). Quanto ao conceito, de modo conciso, o autor pondera que

Revista Digital do LAV - Santa Maria - vol. 9, n. 1, p. 103 - 127. - jan./abr. 2016 ISSN $1983-7348$ http://dx.doi.org/10.5902/1983734819521 
[...] a Cromossonia se propõe, portanto, como uma linguagem possível, de caráter sinestésico não metafórico, articulada através da sucessão de eventos no tempo e no espaço, segundo a seguinte definição : "um evento pode ser considerado cromossônico se, e somente, reúne em sincronia, um som e uma cor, sendo que a frequência da última deve ser igual à do primeiro, multiplicada por 2" (BASBAUM, 1999, p.97).

Isto demonstra a complexidade técnica dos experimentos que estão sendo realizados pelos artistas neste campo, e que buscam converter imagens para sons, ou sons para imagens, pensando na criação composicional exploratória de elementos musicais, tais como ritmos, harmonias, e cores tímbricas dos diversos instrumentos e materiais sonoros. Estes artistas, suas pesquisas, intervenções e estudos, contribuem para o surgimento de novas "sintaxes" dentro do campo da Música Visual, da Tecnologia, e da Arte. Não é raro o surgimento de novas linguagens de programação que desafiam as pessoas a aprenderem coisas novas.

Nesta perspectiva, a união entre Cromossonia, Sinestesia, Música, Tecnologia, Artes e Educação pode representar, para além do caráter interdisciplinar, um desafio cognitivo desafiador, todavia, potencializador de meios mais ousados de apreensão de conhecimentos nestas áreas.

\title{
3 Música Visual como Experiência Imagética Sonora
}

Esta maneira diferenciada de audição do sonoro e do imagético é considerado por Oliveira (2011) como uma negação das "limitações sonoras do mundo", onde o ouvinte pode ter outras experiências estéticas e, talvez, conhecer uma verdadeira experiência sonora deste mesmo mundo:

\begin{abstract}
$\mathrm{Na}$ medida em que se leva a paisagem sonora para uma apresentação no próprio mundo (para fora do teatro, do palco italiano e da sala de concerto), permitindo o movimento do ouvinte no espaço da audição, parece que se pode sair da redução sonora do mundo, apresentando o próprio mundo como uma das camadas $^{11}$ da paisagem sonora (OLIVEIRA, 2011, p.10).
\end{abstract}

Ao explorar estas possibilidades de espaço tímbrico, acústico, todos os músicos participantes do projeto, estão experimentando e fazendo a interação com o universo

\footnotetext{
11 - Nota do autor: "uma paisagem sonora é composta por diversas camadas de eventos sonoros, que podem ser agrupados, nessas camadas, por diversas similaridades entre diversas variáveis (tipo-morfologia temporal, por exemplo).
} 
imagético, e assim, dois modos de pensar se hibridizam esteticamente: a música e a arte visual.

[...] com isso, se evidencia o aspecto híbrido de uma paisagem sonora, uma vez que o hibridismo mostra-se também em outros níveis, além do nível da produção (enquanto dados computacionais). Assim, teríamos a possibilidade de envolver o hibridismo no nível da apresentação ao público, da experimentação da obra, da estética (OLIVEIRA, 2011, p.10).

Pretende-se então, realizar atividades de produção de imagens a partir do som criado, através de captação deste áudio em dispositivos móveis, como o tablet, celulares e notebooks, utilizando programas como o Processing 2.0. Diversos discursos sonoros serão explorados, através da criação de uma composição no estilo da improvisação livre. Este desafio caberá aos músicos da Orquestra Estudantil, sendo que, terão o desafio de criar livremente, sonoridades composicionais improvisatórias, que possam expressar musical, artística e esteticamente, o que será captado por seus olhares e percepções, ao apreciarem as diversas formas e imagens visuais.

Será imprescindível a utilização de dispositivos móveis, já que haverá a criação musical a partir de imagens geradas no Processing 2.0, e consequentemente, a produção de imagens, a partir da mesma sonoridade criada. Essa sonoridade, captada e transmitida à um dispositivo irá gerar imagens computacionais a serem projetadas em tempo real aos alunos.

Pretende-se fazer uso das tecnologias em rede, para tornar possível mais uma pesquisa em educação musical, sendo esta, mediada pelas TIC. A dimensão e contribuição deste estudo estará indo, para além, de simples reprodução de conteúdo e performance musical.

Outrossim, promoverá a interdisciplinaridade, através da realização de uma atividade criativa-composicional - de estilo Improvisatório Livre. Criar-se-á, deste modo, uma composição musical abordando o tema da Música Visual, possibilitada através da fruição e percepção visual dos músicos da orquestra estudantil, que produzirão uma interpretação - discurso sonoro, baseado nas narrativas visuais mediadas pela tecnologias.

Ao pensar acerca do programa Processing 2.0, sabe-se que é uma linguagem de programação, um ambiente de desenvolvimento e uma comunidade online. Desde 2001 tem possibilitado a alfabetização de processamento de software no campo das artes 
visuais e alfabetização visual dentro da área de tecnologia. Inicialmente, o Processing foi criado para servir de caderno de desenho de programações lógicas e para ensinar fundamentos de programação de computadores dentro de um contexto visual. As vantagens do programa Processing é que é gratuito e open-source.

$\mathrm{Na}$ primeira fase da pesquisa, trabalhou-se com imagens geométricas e cores, tais como triângulos, círculos, quadrados, retângulos e linhas retas. As imagens estão programadas para se transpassarem, conforme o Script 1 colocado dentro do Processing 2.0, para fazer gerar o visual. Este script, roda dentro da interface do Processing 2.0, sendo que, no código de programação, há comandos que relacionam o som captado pela placa do computador (AudioInput in;), com imagens geométricas (ellipse (width/2, height/2, in.left.get(0)*1000, in.right.get(0)*1001);), e ainda, com as cores dado pelo código (colorMode(HSB);). Além da associação do som, com as figuras geométricas, este script altera o tamanho da forma geométrica. Esta alteração se dá no sentido horizontal e vertical, e depende da intensidade do som, que é captado tanto no canal direito, como no esquerdo da entrada de som. Para que o som pudesse entrar ao computador foi acionado o microfone da placa de áudio.

Consequentemente, através de algumas das imagens geradas por este Script, já é possível formular narrativas visuais. Todas elas, foram captadas em tempo real, ou seja, no momento exato ao da execução musical dos alunos. Mesmo sendo baseado mais em formas geométricas e cores, pode-se perceber ainda, quando os frames são retirados da filmagem e transformados em fotos, diversas possíveis narrativas. A programação, em determinados momentos da execução musical forma círculos grandes de uma cor, que fica de fundo para quadrados de outra cor, além de ter uma linha que varia de posição dentro do contexto, contribuindo para formar uma imagem colorida.

Esta atividade inicial de interatividade com a tecnologia durante o ensaio geral da Orquestra provocou bastante interesse por parte dos alunos. Em muitas das aulas posteriores vieram questionamentos dos alunos, no sentido de saber quando seria a próxima aula em que teriam Música Visual. Isto demonstra como o esforço em realizar algo diferente com eles é importante e motivador.

Uma das dificuldades avaliadas se deu no sentido das imagens terem apenas o formato de figuras geométricas. Isto motivou novo desafio pra a criação de novos Scripts, com outros formatos, e ainda variando entre um tipo de imagem e outra. Mesmo assim, esta atividade com geração de narrativas visuais no Processing 2.0 trouxe a possibilidade de criação de imagens a partir do som, e este som foi gravado. 
Percebe-se a dinamicidade de formas visuais produzidas pela música, o que atrai muito a atenção de quem está a tocar e observar. Esta é uma aplicação bemsucedida dos conceitos de cromossonia, interatividade, sinestesia, com um grupo de estudantes músicos, em uma escola pública de Ijuí. Em outros momentos da pesquisa houveram análises de diálogos acerca das impressões dos alunos em torno destas experiências com apreciação e produção de Música Visual.

Quanto aos conhecimentos proporcionados pela utilização de recursos imagéticos, pode-se afirmar que existe muita contribuição e vantagens para os ganhos pedagógicos e aprendizados discentes, quando um professor faz uso destes recursos em atividades docentes.

Percebe-se assim, que se deve acreditar no potencial educativo, dinâmico, combinado aos sons, partindo de processos criativos em audiovisual. Quanto à ideia da criação do ambiente realista através do vídeo, ponderado pelo autor acima, pode-se dizer que, de alguma forma, teve aplicabilidade durante a atividade de produção e criação de música visual com a Orquestra Estudantil. Afirma-se isto, uma vez que, enquanto tocavam, os alunos leram a partitura, moveram seus dedos nos instrumentos, prestaram atenção no ritmo, na harmonia e na melodia da música, e ao mesmo tempo, apreciaram as imagens sendo projetadas pelo Processing 2.0, na parede da sala de ensaio. Tudo isto ocorreu simultaneamente. Percebe-se que proposta metodológica de Educação Musical Interativa pode ser concretizada na atividade de ensino e performance de música descrita.

Um dos desafios para a realização de uma prática de Educação Musical Interativa foi a criação de Scripts para projeção de imagens dentro do software Processing 2.0. Para tanto, foi necessário um trabalho colaborativo entre áreas das artes visuais, música e informática. Partindo desta organização, sempre houve momentos de discussão em torno das ideias relativas aos campos do conhecimento citados.

Percebem-se as grandes potencialidades do Processing 2.0 ao ver que é utilizado por artistas desenvolvedores de trabalhos de estética computacional, design, interfaces de visualização, jogos e ambientes interativos. A aplicação deste recurso técnicopedagógico com os alunos da Orquestra trouxe potencializou fazer uso da computação em processos de criação artística realizados com os educandos.

Estes processos abrangeram aulas de experimentação e teste dos Scripts criados para Processing (aspecto tecnológico) e vivência de Sinestesia despertando sentidos da visão e audição (aspecto psicológico), sendo que, ao mesmo tempo existiu a ação dos 
alunos (performance musical criativa). Alguns conhecimentos acerca da tecnologia aplicada às cores foram alcançados. A exploração de cores pelo programa acontece através da exploração do sistema de cores HSB ${ }^{12} / R G B$ (red, green, b/ue), sendo que, dependendo da intensidade do sinal de áudio enviado para o programa, é projetado uma ou mais quadros de cores. Quando o programa dispara (baseado no som trazido pela placa de áudio), aciona o script, produzindo formas geométricas (retângulo, círculo, quadrado, losango, curvas), e em seguida, preenche com cores do sistema HSB.

Esta relação do som com a imagem e a cor, possibilita a vivência de sinestesia e de cromossonia, uma vez que Cromos tem um sentido de cor, enquanto "Sonia" de som. Por este motivo, o Processing pode ser considerado um elemento essencial nas aulas de Educação Musical, que, a partir de sua aplicação no processo de ensino-aprendizagem musical, sugere uma Educação Musical Interativa.

É Interativa, a partir do momento em que os alunos participam do processo de produção, saindo de um modus operandi ${ }^{13}$ performático, para outro em que se tornam "interatores musicais" produtores de narrativas visuais. O benefício disto é o fato de que, normalmente, uma performance musical tradicional não ocasionaria uma apreciação de imagens (em tempo real) nem tampouco daria ao músico a possibilidade de produzir imagens por meio de sua ação, o que caracteriza uma possibilidade de interatividade a mais.

Dada esta asserção, torna-se muito importante acrescentar novos meios didáticos, metodológicos, pensando-se em Educação Musical Interativa, já que traz a possibilidade de novas propostas para a Educação Musical, sendo esta mediada pelos recursos tecnológicos. Trazer o conceito da Música Visual para dentro da sala de aula, em uma escola pública, serve não apenas como superação de um desafio, outrossim, como uma sugestão ousada de aplicabilidade das TIC.

Pensando nesta possibilidade de ampliar e renovar os processos de ensino, realizou-se em uma segunda aula, a apreciação de novos Scripts dentro do programa Processing 2.0. Este script é capaz de gerar círculos de esferas, organizadas de modo que um círculo fique dentro do outro, realizando um movimento rotativo, em direções opostas. A troca de cores das esferas acontece no momento em que o som externo ao

12 HSV é a abreviatura para o sistema de cores formadas pelas componentes hue (matiz), saturation (saturação) e value (valor). O HSV também é conhecido como HSB (hue, saturation e brightness - matiz, saturação e brilho, respectivamente). Esse sistema de cores define o espaço de cor utilizando seus três parâmetros: Matiz (tonalidade): Verifica o tipo de cor, abrangendo todas as cores do espectro, desde o vermelho até o violeta, mais o magenta. Atinge valores de 0 a 360, mas para algumas aplicações, esse valor é normalizado de 0 a 100\%. Saturação: Também chamado de "pureza". Quanto menor esse valor, mais com tom de cinza aparecerá a imagem. Quanto maior o valor, mais "pura" é a imagem. Atinge valores de 0 a 100\%. Valor (brilho): Define o brilho da cor. Atinge valores de 0 a $100 \%$.

13 modus operandi modo pelo qual um indivíduo ou uma organização desenvolve suas atividades ou opera. 
computador, altera as cores, ocasionando então o efeito sinestésico e fazendo valer a ideia de Cromossonia, podendo assim ser apreciada pelos músicos executores da performance musical. Um exemplo das imagens produzidas pelo Script mostrado no código anterior, de modo que ele roda dentro do programa Processing 2.0 são as seguintes:
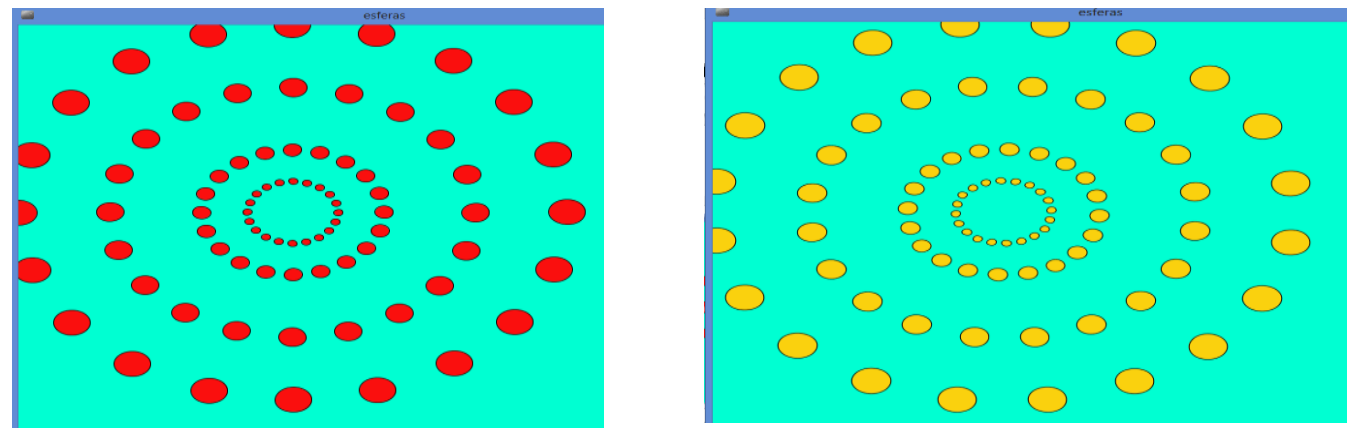

Figura 2: Momento 1 e momento 2 de geração de imagem pelo script

As esferas possuem em momentos da performance musical, colorações diversificadas devido ao script. A observação desta mudança acontece no exato momento em que se tocam acordes, melodias e ritmos, sendo emitidas pelo software alterações nas cores na disposição das esferas da forma circular. As imagens produzidas pelo Script foram bastante apreciadas pelos alunos. Sempre que disparadas pelo som produzido, percebia-se grande atenção dos mesmos nas projeções em data show. Porém, um dos comentários foi acerca do caráter estático da imagem, ou seja, não aconteciam grandes mudanças dentro do tempo. Esta observação trouxe o desafio produzir outro Script, onde aconteçam trocas de imagens em um tempo programado.

As possibilidades visuais geradas com este Script foram as seguintes 

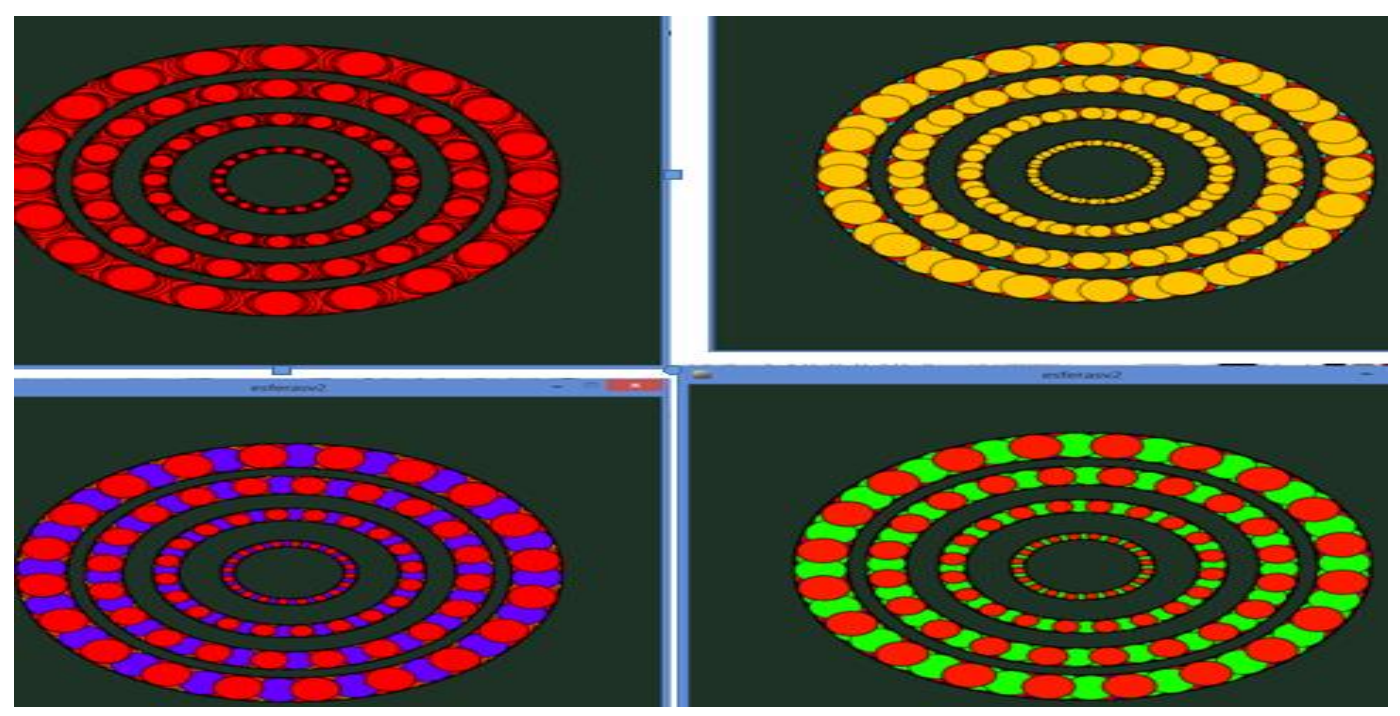

Figura 3: Momentos de geração de imagem pelo Script Esfera v2

O Script seguinte surgiu baseado no código do primeiro citado nesta pesquisa. A programação nova produz uma linha vertical que é alterada de forma dinâmica pelo som, formando em seguida, a imagem de uma espécie de leque colorido. Parte do código criado aproveita o som de entrada da placa de som do computador. O software capta este som através do comando AudioInput in; e em seguida, altera as imagens conforme este som de modo dinâmico. Veja as imagens:
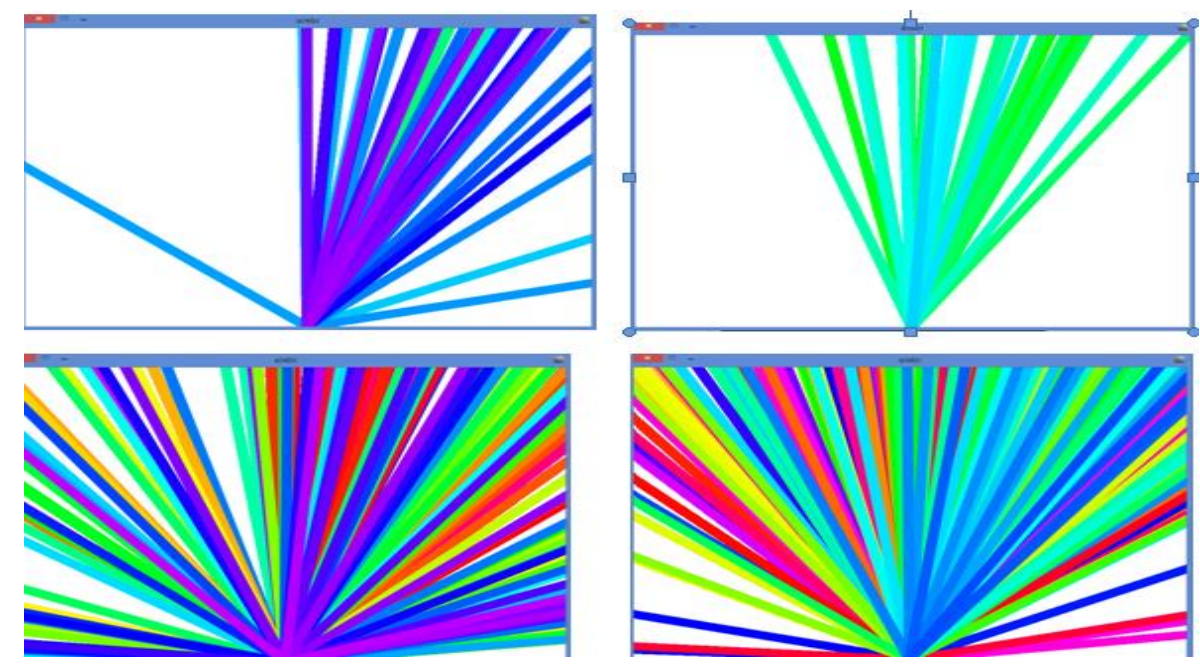

Figura 4: Momentos de geração de imagem pelo Script IDEIA

Esta etapa da pesquisa, em que houve desenvolvimento da tecnologia dos scripts, vem de encontro a uma demanda do Programa de Pós-Graduação em 
Tecnologias Educacionais em Rede da UFSM. O desenvolvimento de uma proposta de metodologia em Educação Musical Interativa, também corrobora os objetivos estipulados pela linha de pesquisa que abrange esta investigação. Pode-se dizer que os Scripts programados para o Processing 2.0, se tornaram ferramentas educacionais tecnológicas em benefício de atividades pedagógicas de apreciação, criação e performance de Música Visual nas atividades realizadas com a Orquestra Estudantil.

Os conteúdos trabalhados via rede de computadores dizem respeito à assuntos trabalhos em aulas de música. O ciberespaço foi utilizado para intermediação interativa das relações de ensino e aprendizagem. Pode-se ver nas fotos abaixo, momentos de interação entre os alunos, e interatividade com a tecnologia descrita.

As fotos da Figura 5 representam outra aula realizada com os alunos, onde se teve o objetivo da realização de performance de produção de Visual, baseado no som da canção My Heart Will Go On - Céline Dion. O objetivo específico da aula foram a realização de gravação de vídeo exercitando a ideia da cromossonia, utilizando-se de uma música já composta e outra improvisada para perceber as diferenças entre elas. Buscaram-se procedimentos preparatórios para criação de uma Música Livre Improvisatória baseada nas Imagens geradas pelos Scripts
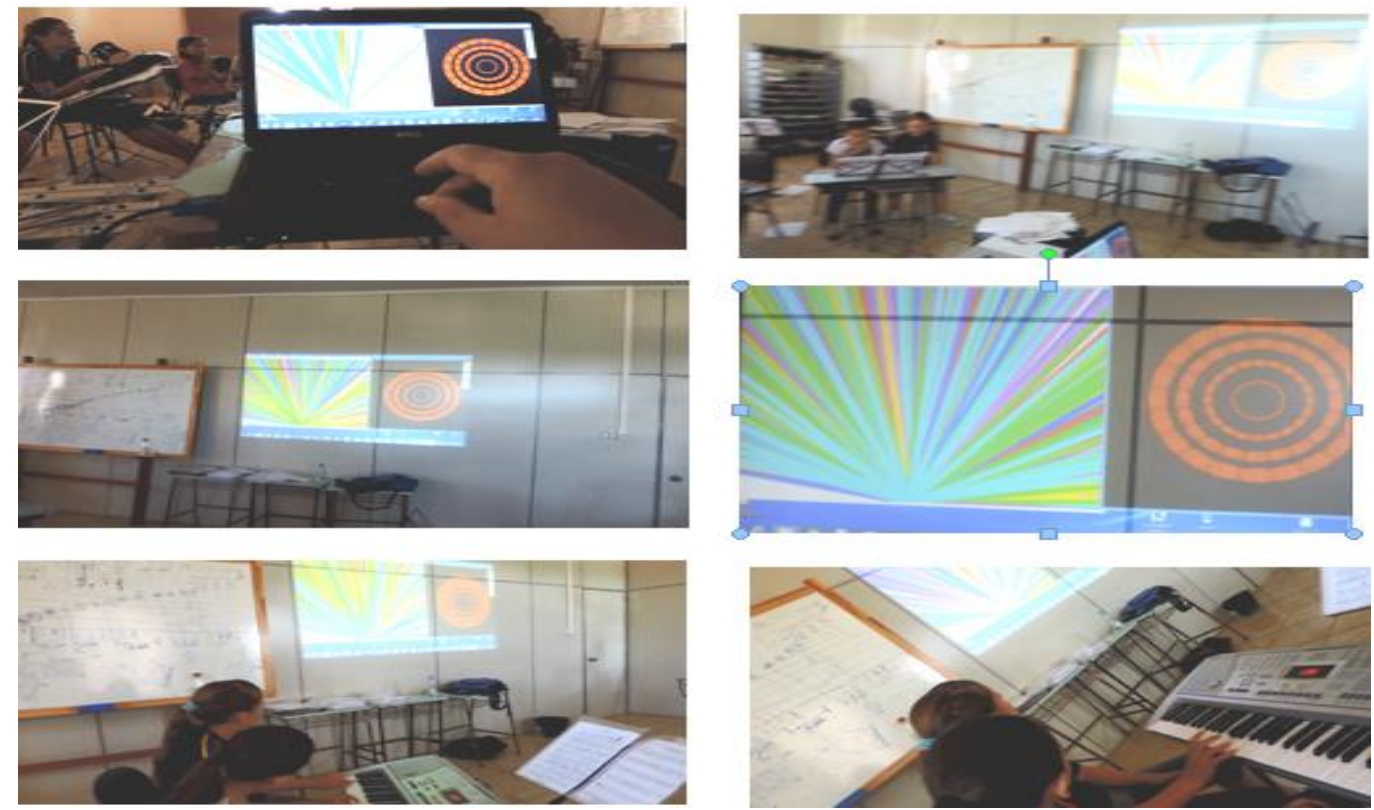

Figura 5 - Alunos realizando performance interativa de Música Visual com Processing 2.0. 
A aula contou com a presença de três alunas flautistas e duas alunas tecladistas. O material utilizado foi quatro partituras da música citada, três flautas, um teclado, um projetor de imagem Epson, um tablet Lenovo para captação de som, uma câmera de filmagem, uma caixa de som, cabos de áudio, 5 estantes de partitura, uma lira. 0 procedimento inicial foi testar imagens projetadas na parede da sala de aula. Foram utilizados os scripts IDEIA e Esfera V2 ao mesmo tempo, uma vez que a narrativa visual se torna mais interessante para os alunos assim. Houve então uma performance musical coletiva em que os alunos tiveram que dedicar atenção na leitura da partitura musical, no instrumento e nas imagens projetadas. Isto exigiu bastante esforço e concentração. Por ser uma atividade diferente daquelas realizadas, onde a música foi improvisada livremente, observou-se que os alunos tiveram que deixar de observar as imagens em momentos da performance. Isto se deu em função da leitura de partitura concomitante ao ato de observar, cuidar os tempos musicais, ritmo melodia, fraseado musical, intensidade musical entre outros.

Outro detalhe que vale a pena comentar diz respeito às alterações das imagens produzidas e a relação como o gênero musical. Ao testar o script utilizando uma música romântica, foi possível perceber uma oscilação menos intensa de imagens geradas pelo Processing. Surge a partir disto, a ideia de trabalhar gêneros musicais tal qual o da música Romântica explorando diferenças de textura ocasionada pelo tipo de agrupamento instrumental utilizado em cada gênero.

A atividade produção de visual se estendeu, passando da performance de uma música pronta para uma música criada de modo aleatório, ou seja, uma música de estilo livre improvisada. A razão de utilizar este método de composição musical é que proporciona uma maior liberdade aos alunos por ser uma música criada na hora da performance. Soma-se a isto, a expressividade criativa possibilitada pela postura menos formal que aquela na qual o músico permanece parado e ereto frente à partitura. A liberdade referida favoreceu diferentes formas de expressão. Um estado emocional mais alegre ocorreu durante a performance, tal como se estivessem interagindo em uma brincadeira. Em se tratando do ato de tocar, a "rigidez formal" anterior é trocada por uma atitude flexível e informal, uma vez que, trocam olhares, se comunicam mais através dos sons, demonstram mais segurança durante a atividade musical que realizam.

As características da composição que os alunos criaram foram igualmente interessantes. Através da escuta da criação delas, pode-se notar que utilizaram diversas 
repetições melódicas, glissandos ${ }^{14}$ e ostinatos ${ }^{15}$. Em um instante posterior ouve-se de fundo a citação da melodia da "música do Titanic" (como é chamada por eles) condensada em meio à um mar de outras notas produzidas livremente. A percepção sonora trazia ainda ideia de acordes fragmentados sendo acompanhado com notas agudas das flautas tocadas em intervalo de terças e segundas maiores. Pode-se considerar que este momento o mais significativo em termos de desenvolvimento de música improvisada com os educandos. A narrativa sonora possibilita visualizar, por exemplo, uma alvorada com assovios difusos e caóticos de pássaros, porém preservando a beleza natural do acontecimento.

O momento foi bastante interessante, por estarem mergulhados na atividade de criação em muitos momentos deixavam de olhar as imagens. Mediante uma pausa geral todos foram orientados que se olhassem o visual (que estavam produzindo e sendo gerado pelo Processing 2.0) eles não estariam praticando sinestesia. Novamente houve melhor qualidade da performance, uma vez que as musicistas concentraram-se mais em olhar para a projeção visual. Foi possível ouvir maior tempo de pausas entre os sons produzidos, o que trouxe uma projeção de cores mais variada do programa Processing. Este momento de performance mais consciente foi feito também com o grupo das flautistas que estavam participando na atividade. Nesta segunda tentativa, os momentos de pausa foram bastante valorizados, uma vez que a partir do silêncio as variações da projeção visual são mais atentamente percebidas pelos interatores.

A consumação da atividade ocorreu após este momento de maior conscientização dos aspectos da Sinestesia. Foi gravado portanto, o audiovisual final, para registro da produção de composição de Música Livre Improvisada baseada nas imagens do Processing 2.0. Para tanto houve necessidade de regência para uma melhor organização das entradas e saídas dos instrumentos. Isto possibilitou maior qualidade devido às trocas tímbricas, ou seja, momentos em que se escutou mais o teclado, as flautas e também os instrumentos de percussão. Foi concretizado assim um dos objetivos propostos na presente pesquisa

O momento de maior aproveitamento da atividade foi o encerramento, onde foi produzido o audiovisual final, com procedimento de criação de uma Música Livre Improvisada mesclada ao Visual. A ideia nesta etapa final foi fazer a produção de um

\footnotetext{
${ }^{14}$ Nota do autor: Técnica de escorregar os dedos sobre as cordas, passando rapidamente por grande extensão da escala musical dos instrumentos.

${ }^{15}$ Nota do autor: Técnica usada para tocar notas musicais onde se utilizam repetições constantes de um mesmo motivo, arpejos e ou frases musicais.
}

Revista Digital do LAV - Santa Maria - vol. 9, n. 1, p. 103 - 127. - jan./abr. 2016

ISSN $1983-7348$ http://dx.doi.org/10.5902/1983734819521 
audiovisual, baseado na composição de Música Livre Improvisada. Partindo deste objetivo, realizou-se então a captação de sons improvisados pelos alunos e pelo professor orientador. A ideia da participação do mediador era fazer a regência de modo a valorizar mais os naipes de instrumentos, as pausas, os momentos de intensidade e principalmente as pausas e retomadas de toques. Como instrumentação, utilizaram-se lira, pandeiro, flautas, percussão do teclado, flautas, pandeiro, triângulos. A regência exigiu bastante desenvoltura, dado que em momentos oportunos da performance foi necessário sinalizar as trocas dos grupos de instrumentos. Com isto obteve-se maior organização da composição, pois o fato de ser "música livre" não significa que se pode realizar música fora de contexto musical.

Além disto, para o professor foi bastante difícil fazer a filmagem, dado que ao instante em que tocava, necessitava manipular a câmera de filmagem e realizar a criação de sons juntamente com os alunos. Coube ao regente conduzir as entradas dos grupos de instrumentos para que melhor fosse observado o efeito da cromossonia. Como já foi explicado anteriormente, por meio desta atividade originou-se uma música livre improvisada de maior qualidade. Ao escutar o áudio resultante desta produção, percebese que existiu maior interação entre os executores de instrumentos, uma vez que cada instrumento teve espaço ampliado para tocar. A atenção dos alunos também foi redobrada e fez valer todas as explicações dadas anteriormente. Estes fatores são sinônimos de maior qualidade na aprendizagem e de maior consciência na assimilação dos elementos que envolvem o tema da Musica Visual.
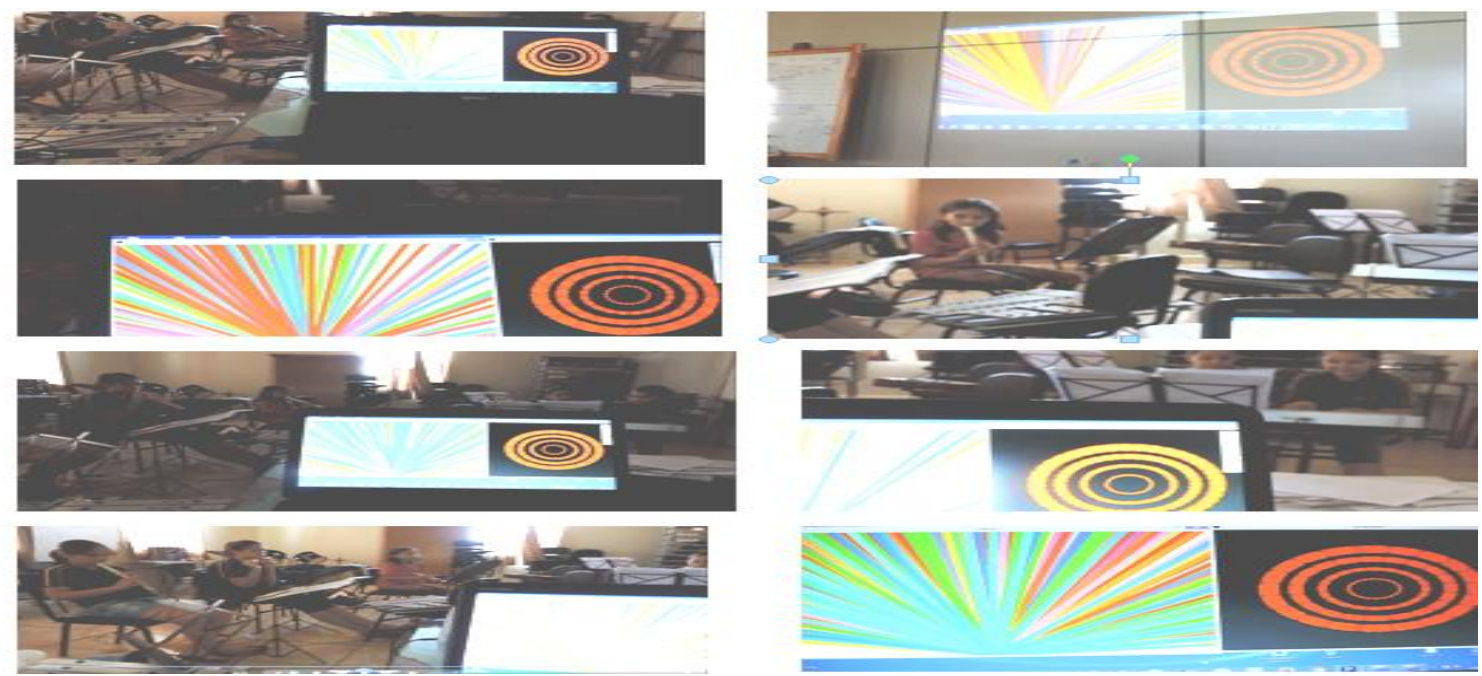

Figura 6 - Produzindo Música Visual e Música Livre Improvisada.

Revista Digital do LAV - Santa Maria - vol. 9, n. 1, p. 103 - 127. - jan./abr. 2016 ISSN 1983 - 7348 http://dx.doi.org/10.5902/1983734819521 
Como encerramento foi realizada uma performance aberta de Música Visual com a Orquestra Estudantil. Tratou-se de uma performance para consolidar todo a trajetória da pesquisa. Alguns resultados foram publicado em umblog construído para divulgar os dados produzidos na pesquisa.

\section{Considerações finais}

Apesar das áreas do campo das Artes serem muito próximas, os diálogos interdisciplinares entre elas são bastante raros. No entanto, as pesquisas em andamento demonstram que as TIC proporcionam meios para que esta interdisciplinaridade aconteça, uma vez que, como se sabe, um computador ligado a uma rede de internet, pode promover diversas formas de interação e interatividade, revelando imenso potencial em comunicação e informação.

O campo da Música se configura como área de estudo muito ampla. Através do conhecimento de sua história, são compreendidos desde o seu surgimento, até as maneiras como o homem tem se relacionado com ela durante a história, seja no passado como na contemporaneidade. Diversas pesquisas no campo da Música e Tecnologias revelam seu caráter interdisciplinar dentro das Artes e ciências humanas. Existem diálogos interdisciplinares, que envolvem fases da história da Arte, como por exemplo, a arte renascentista, barroca, o período clássico, o romantismo, o impressionismo, realismo, expressionismo, que podem ser traduzidos também, no formato de linguagens visuais, musicais e sonoras.

Por esta razão, torna-se possível compreender que, a presente pesquisa, se direcionou nesta perspectiva de interdisciplinaridade e criação, dado que visou contribuir com a criação de metodologias e interfaces da linguagem musical com linguagens de áreas como a Educação em Rede, Educação Musical, bem como a das Artes( Artes Visuais).

Como esta investigação teve como escopo, refletir sobre objetos técno-estéticos interativos e a produção dos mesmos a fim de explorar suas possibilidades de interdisciplinaridade para a área de Educação Musical, dentro de perspectivas da Arte Contemporânea e das Tecnologias Educacionais em Rede, compreende-se que esta meta pode ser alcançada. Possibilitou ainda, ampliação de conhecimentos através de diálogo entre áreas como Artes Visuais, Cultura, Música, Educação Musical, TIC, Informática, Sociologia, Cinema, Produção Audiovisual, Produção Musical e Educação. Os aportes 
teóricos dessas áreas foram fundamentais para concretização do estudo e elaboração de novos conhecimentos.

Muitos recursos tecno-estéticos interativos foram explorados nas atividades de criação de Música Visual, Composição de Música Livre Improvisada, apreciação orientada, com o grupo de Orquestra Estudantil. Esta preocupação, quanto à exploração de recursos tecnológico-educacionais, para o contexto desta pesquisa foi pertinente, de tal modo que, motivou a busca de novos conhecimentos, possibilidades e recursos para as aulas de Educação Musical desenvolvidas com o projeto.

Esta perspectiva mostrou que, embora não existam muitos projetos e pesquisas em funcionamento para a área de Educação Musical em Rede que envolvam softwares, plataformas de interação e interatividade, ambientes virtuais de ensino-aprendizagem, é possível, através de propostas interdisciplinares, desenvolver pedagogias criativas, recursos e atividades diversificadas para serem utilizadas dentro desta modalidade educacional.

Muitas das propostas desenvolvidas no presente estudo podem ter aplicabilidade em outras áreas de conhecimento, como por exemplo, a ideia chave da Educação Musical Interativa. O surgimento desta proposta pedagógica só foi possível por que as TIC possibilitaram o desenvolvimento de atividades de Ensino de Música Interativos, através de experiências interdisciplinares entre os campos da Música, Artes Visuais e Informática e Cinema.

A descoberta de como a utilização de tecnologias digitais podem auxiliar nos processos de ensino e aprendizagem de música em espaços escolares, se evidenciou ao aproveitar conhecimentos do campo da Música Visual, do Audiovisual, da Produção Musical, da utilização do Facebook como ciberespaço educacional. Outro fator que consolidou o alcance do objetivo foi as atividades de produção e desenvolvimento colaborativo de Scripts para Processing 2.0 e de apreciação musical orientada, de modo que, foram trazidos para prática pedagógica com os alunos da Orquestra Estudantil.

Uma descoberta importante, possibilitada através da pesquisa educacional baseada em arte, e metodologia de trabalho por projetos, foi proporcionar uma maior autonomia dos alunos quanto a sua prática performática em música. Tendo em vista que a execução musical é de tal modo restrita à leitura da partitura, interpretação instrumental ou vocal, e em muitos casos, feita sobre a tutela diretiva de um regente, a atividade de criação de Música Visual pode trazer outro sentido para esta performance.

Autonomia, liberdade, interatividade, oportunidade de compor e criar colaborativamente uma música livre improvisada, são alguns exemplos dessa prática 
educacional diferenciada descoberta através de procedimentos metodológicos em Educação Musical Interativa. Percebeu-se que esta iniciativa retira, de certo modo, a passividade performática do aluno músico, fazendo com que não seja apenas intérprete de uma escrita musical pré-determinada. Ao contrário disto, este assume posição de criador e interator no processo da performance musical.

Grande potencial educativo se possibilitou por meio de apreciação musical favorecida por recursos da TIC para os aprendizados musicais dos educandos da Orquestra Estudantil, público-alvo deste estudo. A maior consequência deste uso foi que implicou em aprendizados musicais interativos, como foi visto, nas performances participativas e criações colaborativas entre os participantes. A apreciação coletiva de obras audiovisuais possibilitou a aprendizagem de conhecimentos teóricos da música, de um modo mais ativo e participativo, e até a consolidação de uma composição musical de modo colaborativo.

Tendo a interdisciplinaridade como ponto chave, é importante ratificar que as demais áreas do conhecimento também realizem experiências, pesquisas em parceria com outras áreas. Digo isto, por que este contato interdisciplinar entre áreas me trouxe uma visão menos exígua, do conhecimento de minha própria área de atuação, a Educação Musical. Outrossim, mostrou a importância da área co-irmã, a das Artes Visuais, bem como, da Tecnologia da Informação e Comunicação (TIC), de onde surgiram perspectivas teórico-metodológicas, que me ajudaram a obter uma compreensão mais qualificada em termos de Educação Musical Interativa.

Da mesma maneira, posso considerar que a busca de conhecimento nas outras áreas trouxe uma compreensão maior da minha própria área. O tema da Música Visual é um assunto transdisciplinar, dado que perpassa o campo audiovisual, sendo que, para existir, tem que se apropriar de conhecimentos do Cinema, da Música, das Artes Visuais, Cênicas, da Tecnologia de produção Audiovisual. Por isto, afirmo que, desenvolver este estudo contribuiu com crescimento intelectual e superação de desafios, utilizando-se de um recurso performático tão contemporâneo como a Música Visual.

\section{REFERÊNCIAS}

ALMEIDA Jr., Adolfo Silva de. Conversando a gente se entende: improvisação e procedimentos composicionais. Dissertação de Mestrado. Programa de Pós Graduação da UFRGS. Universidade Federal do Rio Grande do Sul, Porto Alegre, 2009.

Revista Digital do LAV - Santa Maria - vol. 9, n. 1, p. 103 - 127. - jan./abr. 2016

ISSN $1983-7348$ http://dx.doi.org/10.5902/1983734819521 
BASBAUM, Sérgio Roclaw. Fundamentos da Cromossonia - Sinestesia, Arte e Tecnologia. Dissertação. PUC - São Paulo. 1999.

CASTELÕES, Luis Eduardo. Conversão de imagens para sons através de três classes do OpenMusic. "COMUS - Grupo de Pesquisa em Composição Musical da UFJF" Instituto de Artes e Design. Univ. Fed. de Juiz de Fora. MG. 2010.

LUND, Cornelia and LUND, Holger (Eds.); Audio. Visual - On Visual Music and Related Media, Stuttgart. Arnoldsche Verlagsanstalt GMBH, 2009. ISBN: 978-3-89790-293-0 (inclui DVD)

MCNIFF, Shan. Art-Based Research. In: Knowles (Handbook). Editor Jessica Kingsley Publishers. (1998). Disp. em: https://www.unimozarteum.at/files/pdf/fofoe/ff_abr.pdf>. Acess. em: 15 abril de 2012.

MORITZ, William. The dream of color music, and machines that made it possible. Disponível em <http://www.awn.com/mag/issue2.1/articles/moritz2.1.html.> Acessado em 23/09/2014.

OLIVEIRA, André Luiz Gonçalves. Paisagem Sonora como obra híbrida: espaço e tempo na produção imagética e sonora - Curso superior de Música da UFMS. SEMEIOSIS Semiótica E Transdisciplinaridade em Revista - Transdisciplinary Journal Of Semiotics Maio de 2011.

SALLES, Filipe. "Imagens musicais ou música visual - um estudo sobre as afinidades entre o som e a imagem, baseado no filme 'fantasia' (1940) de walt disney" Dissertação de mestrado. Programa de Pós-Graduação em Comunicação e Semiótica da PUC/SP. Defendida em SÃO PAULO, 24 de Junho de 2002, Disponível em <http://www.mnemocine.com.br/filipe/tesemestrado/>. Acesso em Set. 2014.

SULLIVAN, Graeme. Making Space: The Purpose and Place of Practice-led Research. In Practice-led Research, Research-led Practice in the Creative Arts. Organ. por Hazel Smith e Roger Dean. 2009. 